\title{
PULMONARY TUBERCULOSIS IN A "CLOSED" COMMUNITY
}

\author{
Major W. M. ROBINSON, M.B., M.R.C.P. (Ed.), D.T.M. \& H. R.A.M.C., \\ Military Hospital, Tidworth
}

SUMMARY: The incidence of pulmonary tuberculosis in Gurkha soldiers remains higher than in British servicemen living in the same area under the same conditions. The disease is not rapidly progressive and full recovery is the rule. The case histories of $\mathbf{5 0}$ consecutive patients admitted to the Gurkha Chest Centre in West Malaysia and later in Singapore are analysed.

\section{Introduction}

Gurkha soldiers have served the British Crown faithfully and effectively for more than 150 years in all parts of the world: latterly they have been the corner-stone of the British presence in South East Asia, a role that, too soon, they are to relinquish. They are stoics when afflicted with a painful injury, but tuberculosis is too well known to them to cause other than deep respect. A cough and fever are more likely than a wound or minor injury to make them seek medical attention at the earliest possible moment.

The cases selected for this paper comprise the first 50 to have been seen by the author at the Gurkha Chest Centre, which in 1967 moved from Kluang, Johore to the present site in Singapore. The patients were either admitted directly to the centre or transferred on diagnosis from other hospitals in the Far East Land Forces.

After so short a follow-up period, it is not intended to prove that the current standard treatment schedule is superior to any previous one, but to discuss the presentation and early progress of the disease in this "closed" community.

\section{Incidence}

In spite of the high standard of surveillance by the medical services responsible for their health, the men of the Brigade of Gurkhas continue to provide a greater number of cases of active pulmonary tuberculosis than do their British counterparts serving under the same conditions in the same area.

Large (1964) gives the average annual incidence as 5.6 per thousand for the decade 1952-1961 for Gurkha troops, and 0.7 per thousand for British troops in the same area. The author, who either saw or was informed of all cases occurring in Gurkhas in East and West Malaysia and Singapore in the years 1966 and 1967, found the rate to be 3.8 per thousand per annum. At this time the incidence in British soldiers in the Far East Land Forces was 0.4 per thousand.

It is of interest that Large, working on the assumption that, in 1966, ninety per cent of the Brigade would consist of men enlisted after 1951 and therefore have been Heaf-positice or vaccinated with B.C.G., predicted there would be 46 new cases: 53 patients were diagnosed, the increase possibly being due to the less settled circumstances of confrontation in Borneo.

The incidence of tuberculosis in the civilian population of Nepal is relevant both as a focus of infection to which the Gurkha returns every three years on long leave and as an indication whether or not the Nepalese are a "primitive" people where tuberculosis is concerned. No figures are available, but the author on a visit to East 
and West Nepal formed the impression that the disease is common in both the hills from whence come the military jats, or castes, and in the plains through which they pass and where they are recruited. This was confirmed by talking to Nepalese doctors, to members of European medical teams in the country and pension officers of the Brigade. The incidence of tuberculin-positive reactors would provide a clue but Aspin (1947) in a survey carried out at a recruiting depot in India found only 23.2 per cent positive reactors, whereas Robinson (1956) found 51.1 per cent in 2,044 recruits examined in the years 1952-1954.

\section{Severity}

Robinson (1956), describing 140 patients treated by Manley at the Gurkha Sanatorium, then in Kinrara, destroyed the concept previously held that these hillmen suffered a rapidly progressive form of the disease. This denial is confirmed in this paper and those severely ill civilians seen by the author in Nepal appeared to have had symptoms for a considerable time, their poor state of nutrition being a considerable factor. Even so, no cases of miliary tuberculosis were seen in adults.

\section{Age at time of diagnosis}

The average age at the time of diagnosis was 26 years, not perhaps surprising when the population at risk was in the age group 17 to 40 years. Of more interest is that the average length of service before diagnosis was 8.6 years. Of those diagnosed in 1966 five patients were in their first year of service and one had been included in the isonicotinic acid hydrazide (I.N.A.H.) prophylaxis scheme (Dimond 1968).

\section{Method of presentation}

There were three groups of patients: those who reported sick because of symptoms suggestive of pulmonary tuberculosis, 23 (46 per cent), those who were found to have chest lesions at routine mass radiography examinations, 22 (44 per cent) and those who were discovered as a result of contact tracing procedures, 4 ( 8 per cent).

The remaining patient was the recruit taking part in the I.N.A.H. prophylaxis scheme who was found to have fibro-caseous disease after three months' chemotherapy.

\section{Radiological appearances}

\section{Investigations and findings}

Lesions seen in radiographs were classified according to the Diagnostic Standards of the National Tuberculosis Association, New York (1961) as follows:-

Minimal: Where there was no cavitation present and where the total shadowing did not exceed one fifth of the lung field on posteroanterior projection.

Moderately advanced: Where slight to moderate densities extended to the equivalent of the volume of one lung or where dense lesions occupied not more than one third of the volume of one lung. Total number of cavities, if present, should not exceed $4 \mathrm{~cm}$.

Far advanced: Where lesions were more extensive than moderately advanced. 
Using this classification the severity of disease was as follows:-minimal, 20 (40 per cent), moderately advanced, 21 ( 42 per cent), far advanced, 2 (4 per cent). Pleural effusion was demonstrated in 7 (14 per cent) and, cavities were present in 17 (34 per cent) cases.

\section{Sputum}

Acid-fast bacilli were seen on films stained by the Ziehl-Neelsen method, either on direct examination or after culture, in only 24 per cent of cases; no atypical mycobacteria were found.

Thin, Groves and Rapmund (1969) and Ellison et al (1969) have shown that the causative organism of melioidosis is a common inhabitant of drains and ditches in Malaysia and Singapore and the disease can mimic tuberculosis, but in a three month period no Pseudomonas pseudomallei were isolated from the sputum of tuberculosis patients.

\section{Sputum sentivity}

Only one case was found to harbour resistant organisms, resistance to streptomycin, para-aminosalicylic acid (P.A.S.) and isoniazid being detected in some degree. The bacteria, however, were fully sensitive to pyrazinamide, ethionamide, cycloserine, and viomycin.

This freedom from resistance compares favourably with its incidence in Gurkha wives, several of whom in 1966 produced resistant organisms, though this was during treatment and in each case some imperfection in taking drugs was demonstrable.

\section{Tuberculin tests}

The individual's sensitivity to tuberculin was assessed routinely on admission by the multiple puncture method of Heaf (1951). There were only a few exceptions to this, for example, patients with very obvious disease and in whose sputum acid-fast bacilli were seen on admission were not tested.

There were no negative reactors, one Grade 1, and 66 per cent either Grade 3 or Grade 4. The degree of tuberculin sensitivity was, in general, related to a raised erythrocyte sedimentation rate (E.S.R.), but not all Grade 4 reactors had a markedly raised E.S.R. while some Grade 2 did, as shown in Fig 1.

Where previous Heaf tests had been recorded, usually during basic training, those originally exhibiting a Grade 2 or 3 response showed no change, but with one exception all who had been Grade 1 showed enhanced response. It is of interest that four out of six cases of pleural effusion had previously shown a positive reaction.

\section{Erythrocyte sedimentation rate}

The Westergren E.S.R. readings showed a wide scatter (Fig 1).

\section{Haemoglobin concentration}

Anaemia was not a feature of tuberculosis in this series, the average haemoglobin concentration being $14.2 \mathrm{~g} / 100 \mathrm{ml}$ ( 97 per cent); only three patients had haemoglobin concentrates of less than $11.7 \mathrm{~g} / 100 \mathrm{ml}$ (80 per cent). Since hookworm is a common 


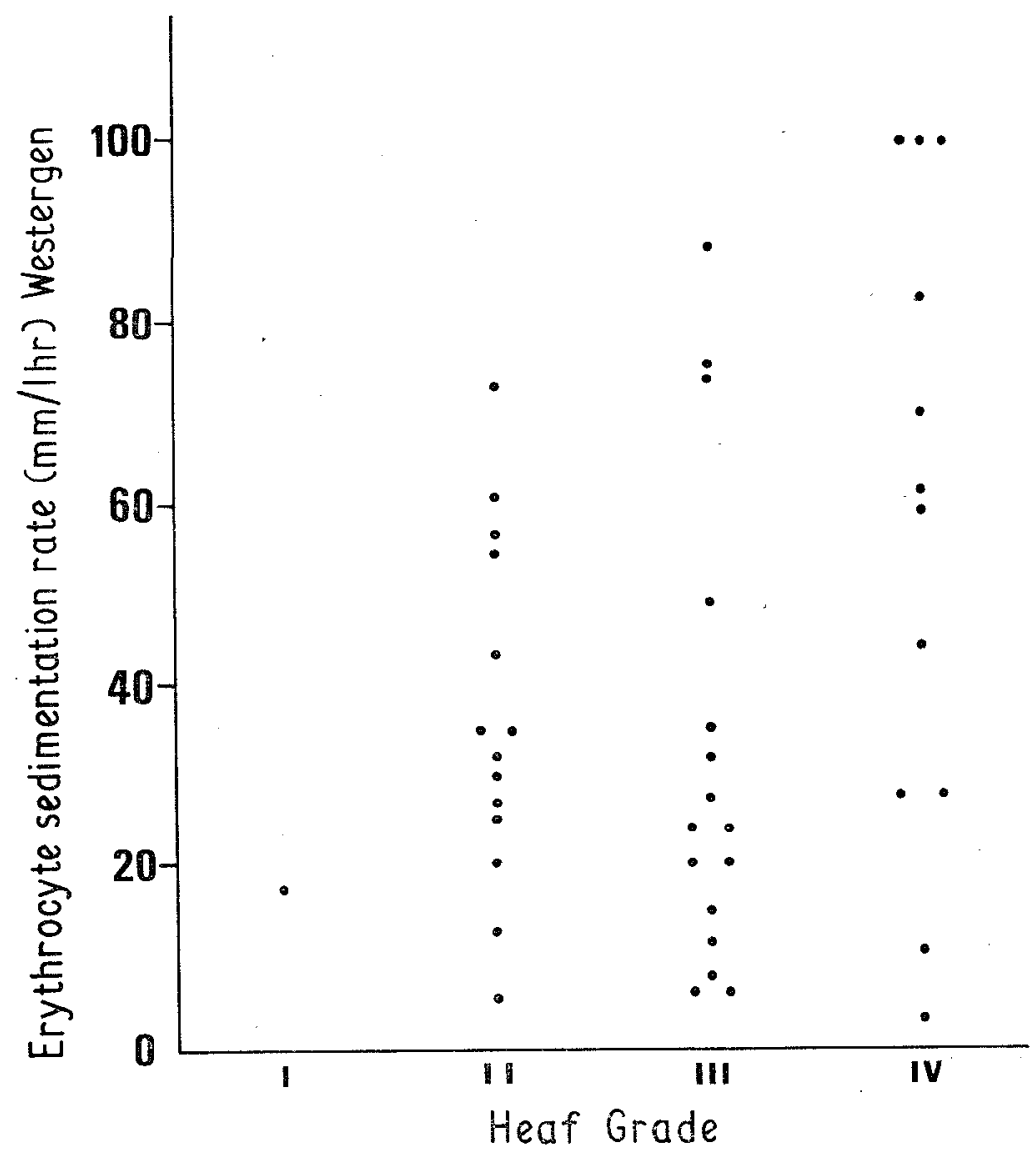

Fig 1. Erythrocyte sedimentation rate related to Heaf grade in forty-three patients.

intestinal (parasite, Bernstein (1964)) found an incidence of 53 per cent in Gurkha recruits, lower levels might have been expected.

\section{Leucocyte count}

In only seven cases did the total white cell count exceed $10,000 \mathrm{ml}^{3}$, the maximum being $15,100 \mathrm{ml}^{3}$ in a not markedly ill patient. This patient also had the highest monocyte response, $1,360 \mathrm{ml}^{3}$ being recorded.

\section{Treatment}

The standard treatment in this series was streptomycin $1.0 \mathrm{~g}$, P.A.S. $12 \mathrm{~g}$ and isoniazid $300 \mathrm{mg}$ daily. Streptomycin was discontinued after $120 \mathrm{~g}$ had been given, by which time the majority of patients were ready to return to their units, continuing P.A.S. and isoniazid for a total of two years.

Bed rest was ordered according to need, and dietary protein was in excess of that normally given to other patients in British military hospitals.

Vermifuges were prescribed as indicated, the commonest parasites being Ankylostoma duodenale and Ascaris lumbricoides. Compound vitamin capsules providing 
pyridoxine $2 \mathrm{mg}$ daily were given routinely and no case of peripheral neuropathy occurred.

\section{Reactions}

Sensitivity reactions to P.A.S. occurred in 12 per cent, to streptomycin in 4 per cent and to streptomycin and P.A.S. in 2 per cent of patients. Desensitisation was successful in all cases except in one who also developed infective hepatitis after apparently successful desensitisation to P.A.S. This drug was then withheld in view of its possible hepatotoxic effects.

\section{Response to treatment}

Response to any form of treatment in tuberculosis can be evaluated by observing conversion from a bacteriologically positive to negative state, radiological improvement and general improvement, reflected by the return to normal of the sedimentation rate.

Bacteriological conversion: All cases having bacteriologically positive sputum were free of acid-fast bacilli on direct examination, confirmed by a subsequent negative culture, after three months treatment.

Cavity closure: Seventeen cases ( 34 per cent) had one or more cavities present on their initial radiograph. By the end of six months treatment fifteen had no demonstrable cavity but two were submitted for resection of single cavities.

Sedimentation rate: The average time for the E.S.R. to return to normal was three months, one case being excluded because a persistently elevated reading was thought to be due to other causes.

\section{Short term results of treatment}

It has not been the purpose of this paper to discuss treatment schedules currently in vogue, nor to assess the final results of treatment of this group of patients, since a sufficiently long period of time has not elapsed, but it is worth noting that all but one patient returned to the normal peacetime routine of the Gurkha soldier including sport, by the end of one year. The remaining soldier who underwent segmental resection returned to duty after fifteen months.

\section{Conclusion}

The incidence of pulmonary tuberculosis in Gurkha soldiers remains higher than that in other servicemen in the same area, but they do not appear to develop a more severe form of the disease, and full recovery is the rule. They are most rewarding people to treat, accepting the necessary discipline without hesitation and, the more their physician has the privilege of knowing them, showing a happy tolerance of their situation not always found in other races.

AsPIN, J. (1947). Tubercle (Lond.) 28, 129.

\section{REFERENCES}

BERNSTEIN, S. (1964). (unpublished data).

DimOND, A. H. (1968). Tubercle (Lond.) 49, 79.

Ellison, D. W., Strauss, J. M., Baker, H. J., Marcarelli, J. L. and Alexander, A. D. (in press).

HeAF, F. R. G. (1951). Lancet ii, 151.

LARGE, S. E. (1964). Tubercle (Edinb.) 45, 321.

Diagnostic Standards and Classification of Tuberculosis (1961). National Tuberculosis Association, New York.

Robinson, T. M. (1956). Proc. roy. Soc. Med. 49, 324.

ThIN, R. N. T., Groves, M. and RAPMUND, G. (in press). 